\title{
PENGARUH LOVE OF MONEY, RELIGIUSITAS, NILAI ETIS, TERHADAP KECENDERUNGAN KECURANGAN AKUNTANSI DAN IDEALISME SEBAGAI VARIABEL MODERATING (STUDI PADA MAHASISWA EKONOMI KOTA PALU)
}

\author{
Irham Pakkawaru
}

\begin{abstract}
This research is the result of a verification study entitled "Effects of love of money, religiosity, and ethical values on the tendency of accounting fraud and idealism as a moderate variable in economics students in Palu. In this research, the researcher used quantitative research method. The data used were primary and secondary data. The research population were students majoring in Economics in Palu. The sampling technique was based on proportional random sampling. The researcher also used multiple regression analysis, different test and residual test. The results of this research showed that variable of love of money, religiosity, and ethical values had an effect on the tendency of accounting fraud, while idealism was not a moderating variable. In addition, there was an idealism difference between female and male students in Palu and there was no difference in the tendency between female and male students in Palu.
\end{abstract}

Keywords: Love of Money, Regression and Simultaneous, Partial

\section{PENDAHULUAN}

Dalam era kemajuan yang semakin berkembang,usaha bisnis juga berkembang dengan pesat pula, kebutuhan akan akuntansi tak terelakan lagi.Akuntan sangat dibutuhkan dalam dunia usaha. Bibit akuntan dihasilkan dari dunia pendidikan, embrio akuntan yang tercipta dari pola pendidikan mengharuskan akuntan yang terbaik.Tantangan akan akuntan yang baik di era globisasi sangat berat dikarenakan kondisi dan situasi yang berbeda dari akuntan terdahulu. Melihat kondisi diatas maka kepercayaan masyarakat terhadap akuntan menjadi besar, harapan atau ekspektasi menjadi taruhan bagi dunia akuntan. 
Fenomena dunia bisnis yang cenderung berfluktuasi dalam tingkat kejujuran adalah pekerjaan rumah yang besar bagi para akuntan. Kaitan yang paling fundamental dalam hal ini adalah masalah laporan keuangan bagaimana perusahaan besar kadang kala melakukan kecenderungan kecurangan demi mencari keuntungan semata banyak contoh dalam kasus perusahaan yang melakukan kecurangan didalam pelaporan keuangan kasus engron dan wordcom yang menjadi headline dizamannya dikarena kasus kecurangan laporan keuangan (Window dressing) ${ }^{1}$, bersamaan dengan kasus tersebut berimbas pada kepercayaan publik dan stakeholder yang menjadi turun terhadap akuntan,kalau melihtat alasan yang menjadi dasar mengapa masyarakat pada saat itu begitu skeptis terhadap akuntan adalah hal yang wajar disebabkan opini dari laporan keuangan dikeluarkan dan menjadi otoritas seorang auditor,namun kasus engron dan wordcom menjadi contoh perilaku kurang etis bagi dunia akuntan Menyikapi hal tersebut mau tidak mau,suka atau tidak suka akuntan harus mempunyai integritas yang mumpuni dan kuat.Kekuatan seorang akuntan dimulai pada saat akuntan memulai dalam dunia pendidikan.

idealisme serta religiusitas adalah hal yang paling fundamental yang harus dimiliki oleh seorang akuntan.Integritas yang kuat dalam diri akuntan boleh jadi berasal dari kekuatan idealisme dan religiusitas dalam dirinya.Zaman yang berubah, kebutuhan yang semakin meningkat,gaya hidup yang cenderung materialistik adalah merupakan tantangan tesendiri bagi para akuntan untuk dapat bertahan dari tantangan diatas.

Materalisme yang terlampau berlebihan dalam diri seseorang juga menjadi alasan mengapa seseorang menjadi hilang integritas dalam dirinya.hal ini pernah duji oleh lukita tripermata ${ }^{2}$ bahwa terdapat hubungan antara love of money terhadap kecenderungan kecurangan akuntansi.

\footnotetext{
${ }^{1}$ Dikutip dalam skripsi Celvia, Analisis Hubungan Antara Love Of Money Dengan Prespsi Etika Mahasiswa Akuntansi, (Semarang; 2011), h.2

${ }^{2}$ Pengaruh love of money, perilaku etis mahasiswa dan komitmen organisasi terhadap kecenderungan kecurangan akuntansi l dengan gender sebagai variabel moderating (Palembang; 2016), h.55
} 


\section{KAJIAN PUSTAKA}

\section{Kajian Terdahulu yang Relevan dengan Peneliti}

Putu pandu prabowo dan A.A.G.P Widanaputra $^{3}$ dalam penelitiannya pengaruh love of money, machiavelllian dan idealisme pada persepsi etis mahasiwa akuntansi penelitian ini menggunakan metode kuantitatif yang bertujuan mengetahui pengaruh love of money machiavelllian dan idelisme terhadap nilai etis mahasiswa akuntansi ,metode penentuan sampel pada peneltian ini menggunakan tehnik purposive sampling.Populasi penelitian ini yaitu 200 orang mahasiwa program studi akuntansi angkatan 2014 Fakultas Ekonomi Udayana Bali ,analisa data yang digunakan oleh peneliti ini menggunakan tehnik regresi linear berganda adapun hasil penelitiannya yaitu love of money berpengaruh negatif pada persepsi etis, machiavelllian berpengaruh negatif pada persepsi etis dan idealisme berpengaruh positif pada persepsi etis.

Ridayanti, Dekeng setyobudiarto ${ }^{4}$ dalam penelitian ini menguji hubungan antara gender, love of money, machiavelllian dan nilai etis mahasiswa,sampel dalam penelitian ini adalah mahasiwa prodi akuntansi Universitas PGRI Yogyakarta dengan tehnik stratified random sampling dengan jumlah sampel 120 orang.hasil penelitian ini membuktikan bahwa machiavelllian berpengaruh signifikan terhadap perikau etis dan nilai etis terdapat perbedaan berdasarkan gender.

Lukita Tripermata ${ }^{5}$ dalam penelitian ini yang berjudul pengaruh love of money,nilai etis mahasiswa dan komitmen organisasi terhadap kecenderungan kecurangan akuntansi dengan gender sebagai variabel moderating dalam penelitian ini sampel yang digunakan adalah mahasiswa akuntansi dan manajemen universitas

\footnotetext{
${ }^{3}$ Putu pandu prabowo dan A.A.G.P Widanaputra, Pengaruh love of money, machiavellian dan idealisme pada presepsi etis mahasiswa akuntansi jurnal akuntansi vol 231 april 2008 (Bali: 2018)

${ }^{4}$ Hubungan Antara love of money, machiavellian dengan persepsi etis analis berdasarkan perpektif gender (Yogyakarta: 2017)

${ }^{5}$ Lukita Permata, Pengaruh love of money, perilaku etis mahasiswa dan komitmen organisasi terhadap kecenderungan kecurangan akuntansi $l$ dengan gender sebagai variabel moderating (Palembang; 2016)
} 
52 | MUSA WA, Vol. 12 No.1 Juni 2020 : 49-72

indoglobal mandiri palembang dengan jumlah responden sebanyak 81 responden dengan alat analisis regresi berganda adapun hasil penelitiannya adalah terdapat pengaruh love of money terhadap kecenderungan kecurangan akuntansi

Firdausia oktaviana,maslichah dan $\mathrm{M}$ colid mawardi ${ }^{6}$ dalam penelitian yang berjudul Analisis pengaruh love of money,gender,religius terhadap persepsi etis mahasiswa akuntansi bahwa variabel gender tidak berpengaruh terhadap love of money dan persepsi etis adapun sampel penelitian ini adalah mahasiswa PTN dan PTS dikota Malang dengan jumlah responden 170 dan alat analisis yang digunakan adalah Structure ecution model (SEM).

\section{Tabel 3}

\section{Perbandingan penelitian saat ini Dengan penelitian terdahulu}

\begin{tabular}{|c|c|c|c|c|c|}
\hline Keterangan & $\begin{array}{l}\text { Putu pandu prabowo } \\
\text { dan A.A.G.P } \\
\text { Widanaputra (2018) }\end{array}$ & $\begin{array}{c}\text { Ridayanti,Dekeng } \\
\text { setyobudiarto (2017) }\end{array}$ & $\begin{array}{c}\text { Lukita } \\
\text { Tripermata } \\
(2016)\end{array}$ & $\begin{array}{c}\text { Firdausia } \\
\text { oktaviana,maslichah } \\
\text { dan } \mathrm{M} \text { colid } \\
\text { mawardi }\end{array}$ & $\begin{array}{c}\text { Penelitian saat } \\
\text { ini }\end{array}$ \\
\hline $\begin{array}{l}\text { Variabel } \\
\text { bebas }\end{array}$ & $\begin{array}{c}\text { Love Of } \\
\text { Money,Machiavellian } \\
\text { dan idelisme, }\end{array}$ & $\begin{array}{c}\text { Love Of } \\
\text { Money,Machiavellian }\end{array}$ & $\begin{array}{c}\text { Love Of } \\
\text { Money,nilai etis } \\
\text { dan komitmen } \\
\text { organisasi } \\
\end{array}$ & $\begin{array}{l}\text { Love Of Money, } \\
\text { Gender,religius }\end{array}$ & $\begin{array}{c}\text { Love of money } \\
\text {,Religiusitas } \\
\text {,nilai etis }\end{array}$ \\
\hline $\begin{array}{l}\text { Variabel } \\
\text { terikat }\end{array}$ & Persepsi etis & Persepsi etis & $\begin{array}{c}\text { Kecenderungan } \\
\text { kecurangan } \\
\text { akuntansi }\end{array}$ & Persepsi etis & $\begin{array}{c}\text { Kecenderungan } \\
\text { kecurangan } \\
\text { akuntansi }\end{array}$ \\
\hline $\begin{array}{c}\text { Variabel } \\
\text { Moderating }\end{array}$ & Tidak ada & Gender & Gender & Tidak ada & idealisme \\
\hline Jenis data & Data primer & Data primer & Data primer & Data primer & Data primer \\
\hline $\begin{array}{l}\text { Tehnik } \\
\text { pengambilan } \\
\text { sampel }\end{array}$ & Purposive sampling & $\begin{array}{l}\text { Statified random } \\
\text { sampling }\end{array}$ & $\begin{array}{l}\text { Purposive } \\
\text { sampling }\end{array}$ & $\begin{array}{c}\text { Proporsional } \\
\text { random sampling }\end{array}$ & $\begin{array}{l}\text { Proporsional } \\
\text { random } \\
\text { sampling }\end{array}$ \\
\hline $\begin{array}{c}\text { Tehnik } \\
\text { analisa data }\end{array}$ & Regresi berganda & T test & Regresi berganda & $\begin{array}{l}\text { Strukture Eqution } \\
\text { model }\end{array}$ & $\begin{array}{c}\text { Regresi } \\
\text { berganda,T test } \\
\text { dan uji residual }\end{array}$ \\
\hline Lokasi & Bali & Yogyakarta & Palembang & Malang & Palu \\
\hline
\end{tabular}

\section{(Malang)}

${ }^{6}$ Analisis pengaruh love of money,gender,religius terhadap persepsi etis mahasiswa akuntansi 


\section{Konsep dan Teori yang Relevan}

\section{A. Teori Keagenan}

Jensen dan Meckling (1976) mendefinisikan hubungan keagenan sebagai sebuah kontrak dimana salah satu atau lebih prinsipal menyewa orang lain(agen) untuk melakukan beberapa jasa untuk kepentingan mereka dengan mendelegasikan beberapa wewenag untuk membuat keputusan kepada agen.pemisahan kepemilikan dan pengendalian menyebabkan manajemen bertindak tidak sesuai dengan keinginan prinsipal.Dalam melaksanakan tugas manajerial,manajerial memiliki tujuan pribadi yang bersaing dengan dengan tujuan prinsipal didalam memaksimalkan kemakmuran pemegang saham.pemisahan kepemilikan dan pengendalian perusahaan disebut konflik keagenan(Agency teory). ${ }^{7}$

\section{B. Love of money}

Tang $1992^{8}$ menyatakan bahwa banyak orang bepikir bahwa uang atau penghasilan merupakan suatu untuk menilai keberhasilan seseorang. Uang memiliki dampak signifikan pada masyarakatmotivasi, perilaku, dan kinerja. Skala Etika Uang (MES) dulu danbaru-baru ini dikembangkan, dimana arti uang diperiksa dalam asampel 249 karyawan penuh waktu di Amerika Serikat. Enam utamafaktor (30 item) diidentifikasi menggunakan skala MES: baik, jahat,prestasi, rasa hormat, anggaran, dan kekuasaan. Dalam penelitian kali inibertujuan untuk mengembangkan jangka pendek dari Skala Etika Uang.

\section{Religiusitas}

Menurut Atang ${ }^{9}$ dalam bukunya Metodologi studi Islam menjelaskan bahwa religiusitas itu adalah sikap hidup seseorang berdasarkan pada nilai-nilai yang

${ }^{7}$ Jensen dan Meckling dalam buku Teori Akuntansi Konsep Dan Empiris (Malang: BP STIE Malang kucecwara, 2008), h.227

${ }^{8}$ Tang TLP" The Meaning Of Money Revisited The Development Of The Money Ethic Scale (34 th Annual metting of the southwestern psychological Association.1988

${ }^{9}$ Dikutip pada artikel memahami makna religiusitas Islachul imam (Http ;// islachul 08.blogspot.co.id/2014/02/ pada tanggal 04 April 2017 
54 | MUSA WA, Vol. 12 No.1 Juni $2020: 49-72$

diyakininya. Religiusitas dalam konteks keislaman pun sudah tersirat dalam ajaran agama Islam dalam proses menjalankan ajaran agama secara kaffah atau menyeluruh. Allah Berfirman dalam Al-Quran surat Albaqarah ayat 208:

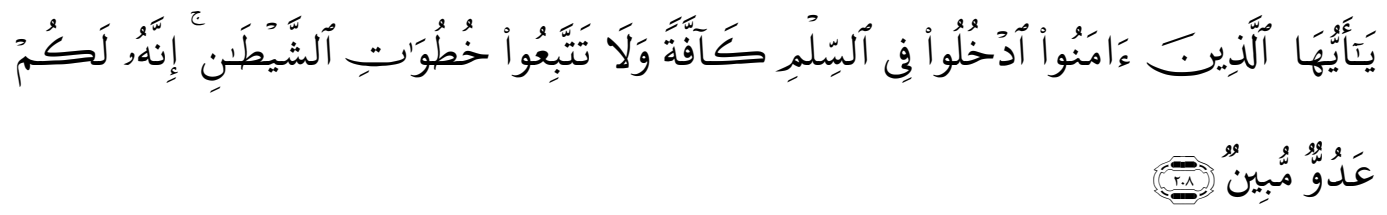

208. Hai orang-orang yang beriman, masuklah kamu ke dalam Islam keseluruhan, dan janganlah kamu turut langkah-langkah syaitan. Sesungguhnya syaitan itu musuh yang nyata bagimu.

Adapun beberapa pendapat memaknai makna religiusitas dalam makna berperilaku. Dimensi religiusitas dan spiritual memberikan pengaruh dalam bertindak. $^{10}$

D. Idealisme

Idealisme menurut falah ,2006 dalam jurnal putu pandu prabowo dan A.A G.P widana putra ${ }^{11}$ suatu perbuatan atau tindakan dengan perkiraan dapat memberikan efek atau hal yang diinginkan dan diharapkan. Seseorang yang idealis akan berbuat selalu mengikuti hati nurani dan berbuat sesuatu memikirkan dampak positif atau dampak negatif dari perbutannya dan sebisa mungkin melakukan tindakan untuk tidak pernah melukai hati dan moral orang lain atau dampak yang kurang baik.

E. Etika

Berbicara tentang etika dalam islam tentu saja tidak bisa lepas dari bagaimana posisi etika itu dalam skema ajaran islam secara menyeluruh. ${ }^{12}$ dan bagaimanapun perilaku mencerminkan ahlak seseorang atau dengan kata lain perilaku berelasi dengan etika

\footnotetext{
${ }^{10}$ Yusuf Qurnia, Quantum Ibadah Mengelola Diri Dengan Mengenal Perjalanan Hidup (Solo; Tiga serangkai, 2008)

${ }^{11}$ Putu pandu prabowo dan A.A.G.P Widanaputra, Pengaruh Love Of Money,Machiavellian Dan Idealisme Pada Presepsi Etis Mahasiswa Akuntansi jurnal akuntansi vol 231 april 2008 (Bali: 2018)

${ }^{12}$ Muhammad djakfar, Anatomi Perilaku Bisnis Dialetika Etika Dan Realitas (UIN Malang press2009)
} 
apabila seseorang taat pada etika maka kecenderungan akan menghasilkan perilaku yang baik dalam setiap aktivitasnya atau tindakannnya. ${ }^{13}$

F. Fraud Triangle

Fraud examiners manual (edisi 2006) menyebut donald r cressey sebagai mahasiswa terpandainya Edwin H. Suterland. Kalau penelitian Suterland dipusatkan pada kriminalitas masyarakat atas. Cressey mencari arah lain dalam penelitiannya. ${ }^{14}$ Theodorus ${ }^{15}$ menggunakan istilah fraud tanpa menerjemahkannya misalnya dengan istilah "kecurangan" dalam perkembangannya hipotesis ini dikenal dengan fraud Triangle atau segitiga fraud yang dapat dilihat dari gambar ini

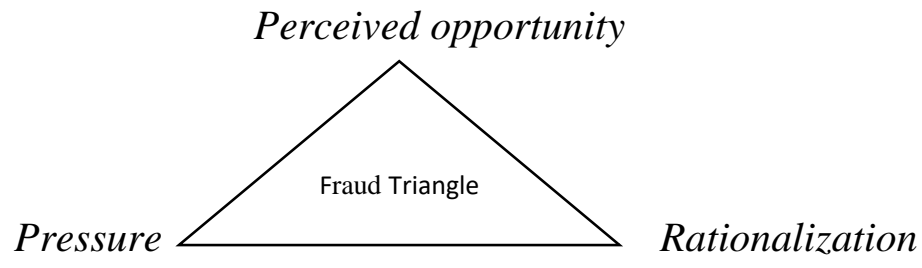

Sudut pertama dari segitiga itu diberi judul pressure yang merupakan perceived nonsharable financial need, sudut keduanya perceived opportunity, sudut ketiga rationalization.

\section{METODE PENELITIAN}

\section{Data dan Sumber Data}

Data adalah segala informasi yang disajikan dan diolah untuk suatu kegiatan penelitian sehingga dapat dijadikan dasar dalam pengambilan Keputusan ${ }^{16}$ Adapun sumber data yang digunakan dalam penelitian ini adalah data primer. Data primer

\footnotetext{
${ }^{13}$ Muhammad Djakfar, Anatomi Perilaku Bisnis Dialetika Etika Dan Realitas (UIN Malang press, 2009)

${ }^{14}$ Dikutip dalam Theodorus M Tuanakota, Buku Akuntansi Forensik Dan Audit Investigative (Salemba Empat; 2010)

${ }^{15}$ Ibid.

${ }^{16}$ Muhammad, Metode penelitian Ekonomi Islam Pendekatan Kuantitatif, (Jakarta; PT Raja Grafindo Persada, 2008), h.97
} 
adalah data yag dikumpulkan dan diolah sendiri oleh suatu organisasi atau perseorangan langsung dari objeknya. ${ }^{17}$

\section{Populasi dan Sampel}

Populasi dalam penelitian ini adalah mahasiswa kota Palu jurusan Ekonomi di kota Palu. Adapun tehnik yang digunakan yang digunakan untuk mengambil sampel dalam penelitian ini adalah yaitu tehnik pengambilan yaitu tehnik pengambilan sempel berdasarkan Proporsional random sampling. ${ }^{18}$

\section{Uji Instrumen Penelitian}

\section{A. PengujianValiditas}

Uji validitas data digunakan untuk mengukuir sahnya atau validnya data suatu kuesioner $^{19}$. Suatu kuestioner dikatakan valid jika pertanyaan pada kuestioner mampu mengungkapkan sesutau yang akan diukur oleh kuestioner tersebut ujian signifikansi dilakukan dengan membandingkan $r$ hitung maupun $r$ tabel untuk degree of freedom .

B. Pengujian Reabilitas

Uji Reabilitas adalah alat untuk mengukur suatu kuestioner yang merupakan indikator dari variabel atau konstruk .suatu kuestioner dikatakan reliabel atau handal jika jawaban seseorang terhadap pernyataan adalah konsisten atau stabil dari waktu kewaktu diuji dengan menggunakan koofisien cronbach's Alpha jika nilai koofesien alpha lebih besar dari 0,7 maka disimpulkan bahwa instrumen penelitian tersebut handal atau realibel ${ }^{20}$ reliabel atau handal.

\section{Uji Asumsi klasik}

Uji Asumsi klasik menggunakan Uji Normalitas, Uji Multikolonieritas, dan Uji Heteroskedastisitas

\footnotetext{
${ }^{17}$ Muhammad, Rajawali Press, h. 101

${ }^{18}$ Sugiyono, h.122

${ }^{19}$ Imam Ghozali, Aplikasi Multivariat dengan program Spss21 (Semarang; Undip, 2013), h.52

${ }^{20}$ Ibid, h. 47
} 


\section{Tehnik Analisa Data}

\section{Analisis Regresi Berganda}

Regresi berganda bila peneliti bermaksud meramalkan bagaimana keadaan (naik turunya) variabel dependen (Kriterium) bila dua atau lebih varibel independen sebagai faktor dimanipulasi (dinaikturunkan nilainya). ${ }^{21}$ Dalam penelitian ini yang menjadi varibel bebas adalah Love of money (X1), religiusitas (X2) nilai etis (X3) sedangkan variabel terikat adalah kecenderungan kecurangan akuntansi (Y) hubungan antara variabel bebas dapat dirumuskan sebagai berikut:

$\mathrm{Y}=\mathrm{a}+\mathrm{b} 1 \mathrm{x} 1+\mathrm{b} 2 \times 2+\mathrm{b} 3 \times 3+\mathrm{bkxk}+\mathrm{e}$

Dimana :

$\mathrm{Y}=$ Variabel dependen

$\mathrm{X} 1-\mathrm{XK}=$ Variabel independen

$\mathrm{a}=$ Intercept/constanta

b1-bk= Koofisien regresi

$\mathrm{e}=$ Eror atau standar eror

Pengujian ini bertujuan untuk melihat pengaruh dan hubungan antara variabel independen dan dependen. Variabel indepnden dalam penelitian ini adalah Love of money (X1) ,religiusitas (X2) nilai etis (X\#3) sedangkan variabel terikat adalah kecenderungan kecurangan akuntansi (Y) formulasi regresi linear berganda maka akan diperoleh persamaan sebagai berikut:

$\mathrm{Y}=\mathrm{a}+\mathrm{b} 1 \times 1+\mathrm{b} 2 \times 2+\mathrm{b} 3 \times 3+\mathrm{e}$

Keterangan

$\mathrm{Y}=$ kecenderungan kecurangan akuntansi

$\mathrm{b} 1-\mathrm{b} 2=$ Koofesien regresi

$\mathrm{X} 1=$ Love of money

$\mathrm{X} 2=$ religiusitas

$\mathrm{X} 3 \quad=$ nilai etis

e $\quad=$ Standar eror

\footnotetext{
${ }^{21}$ Sugiyono, h. 275
} 
58 | MUSA WA, Vol. 12 No.1 Juni $2020: 49-72$

\section{Uji beda independen ( $T$ test)}

Uji beda $t$ test dilakukan dengan cara membandingkan perbedaan antara dua nilai rata-rata dengan standar eror dari perbedaan rata-rata dua sampel dan standar eror perbedaan dalam penelitian ini dalam nilai rata-rata terdistribusi secara normal membandingkan rata-rata dua grup yang tidak berhubungan satu dengan yang lain. ${ }^{22}$ Uji Moderated Regression Analysis (MRA) dengan metode uji residual untuk menguji pengaruh deviasi penyimpangan dari suatu model. ${ }^{23}$

\section{HASIL PENELITIAN}

\section{A. Hasil Pengujian Asumsi Klasik}

Uji Asumsi klasik dilakukan dengan tujuan untuk mengevaluasi model regresi berganda yang digunakan untuk menghasilkan nilai yang sesunguhnya. Persamaan regresi berganda yang dilakukan uji asumsi klasik adalah:

Dalam penelitian ini yang menjadi varibel bebas adalah Love of money (X1), religiusitas (X2) nilai etis (X3) sedangkan variabel terikat adalah kecenderungan kecurangan akuntansi (Y) hubungan antara variabel bebas dapat dirumuskan sebagai berikut:

$$
\begin{aligned}
& Y=a+b 1 \times 1+b 2 \times 2+b 3 \times 3+b k x k+e \\
& \text { Dimana : } \\
& Y=\text { Variabel dependen } \\
& \text { X1-XK = Variabel independen } \\
& a=\text { Intercept/constanta } \\
& \text { b1-bk= Koofisien regresi } \\
& \text { e= Eror atau standar eror }
\end{aligned}
$$

\footnotetext{
${ }^{22}$ Imam Ghozali, Aplikasi Multivariat dengan program Spss 21 (Semarang; Undip,2013), h.65

${ }^{23}$ Ibid, h.24
} 
Pengujian ini bertujuan untuk melihat pengaruh dan hubungan antara variabel independen dan dependen. Variabel indepnden dalam penelitian ini adalah Love of money (X1), religiusitas (X2) nilai etis (X3) sedangkan variabel terikat adalah kecenderungan kecurangan akuntansi $(\mathrm{Y})$ formulasi regresi linear berganda maka akan diperoleh persamaan sebagai berikut:

$\mathrm{Y}=\mathrm{a}+\mathrm{b} 1 \mathrm{x} 1+\mathrm{b} 2 \times 2+\mathrm{b} 3 \times 3+\mathrm{e}$

\section{Keterangan}

$\mathrm{Y}=$ kecenderungan kecurangan akuntansi

b1-b2 = Koofesien regresi

$\mathrm{X} 1=$ Love of money

$\mathrm{X} 2=$ religiusitas

X3 = nilai etis

$\mathrm{e} \quad=$ Standar eror

untuk itu asumsi klasik terdiri dari uji normalitas data, multikolonirietisat data, hetersokdisitas data.

\section{B. Hasil Uji Normalitas Data}

Pengujian normalitas data menggunakan analisis grafik dilakukan dengan menggunakan histogram dengan menggambarkan variabel dependent sumbu vertikal sedangkan nilai residual tersandarisasi digambarkan sebagai sumbu horizontal. ${ }^{24}$

\section{Gambar 1}

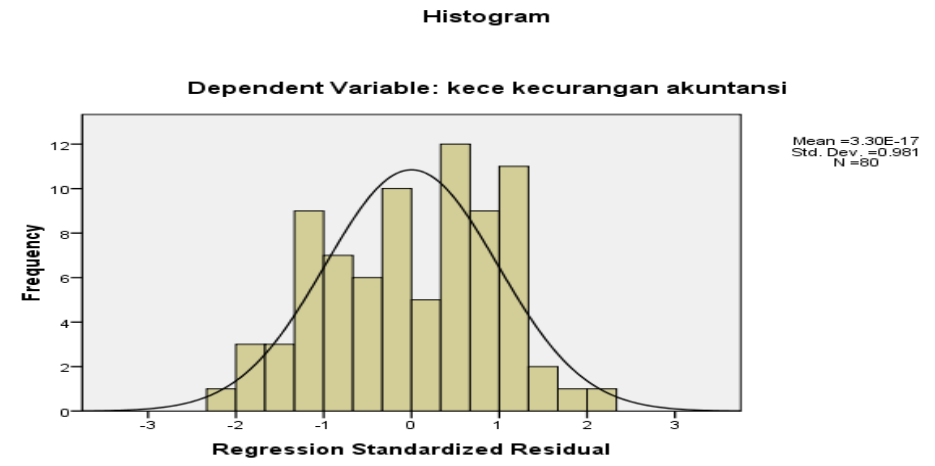

\footnotetext{
${ }^{24}$ Suliyanto, Ekonomika Dan Terapan Teori Dan Apliksi Dengan Spss, (Yogyakarta: Andi Offset, 2011), h. 69
} 
60 | MUSA WA, Vol. 12 No.1 Juni $2020: 49-72$

Pada Out put Histogram berdasarkan tampilan bahwa kurva dependent dan regression standardised residual membentuk gambar seperti lonceng oleh karena itu berdasarkan uji normalitas data,analisis regresi layak digunakan.

\section{Gambar 2}

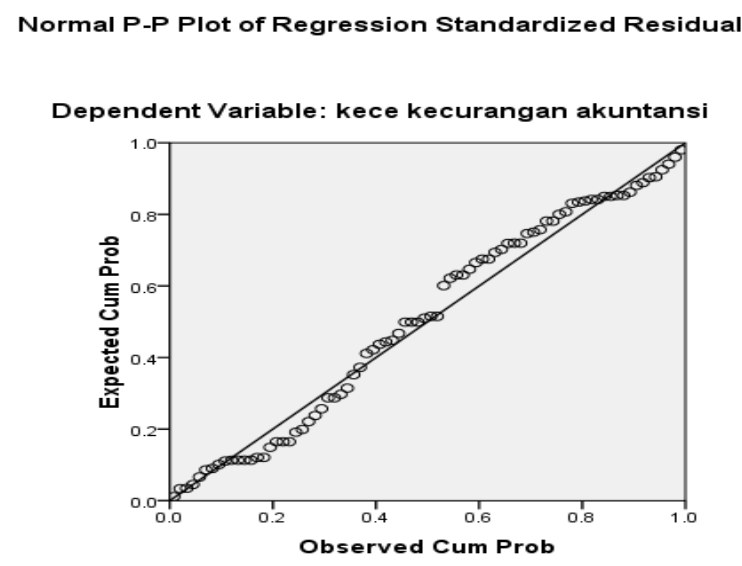

Berdasarkan tampilan normal p-plot regresssion standardized terlihat bahwa titik-titik menyebar sekitar garis diagonal.oleh karena itu bersarkan uji normalitas data analisis regresi layak digunakan.

\section{Hasil Uji Multikolinieritas Data}

Pengujian ini bertujuan untuk mengetahui apakah yang model regresi ditemukan adaya rkorelasi dengan sesama varabel bebabaik seharusnya tidak terjadi korealsi antara variabel independen.Model regresi yang pada Penelitian ini Variance influence factor sebagai acuan ada tidaknyad Multikolinieritas data diantara variabel bebas.nilai toleransi yang rendah sama dengan dengan nilai VIF tinggi( karena $\mathrm{VIF}=1$ ) nilai cut off dipakau untuk menunjukan ada Multikolinieritas data dengan nilai tolerance $\leq 10$ atau $\mathrm{VIF} \geq 10^{25}$

\section{h. 105}

${ }^{25}$ Imam Ghozali, Aplikasi Multivariat dengan program Spss 21 (Semarang; Undip, 2013), 
Irham Pakkawaru, Pengaruh Love of Money ... | 61

Gambar 3

Coefficients $^{\mathrm{a}}$

\begin{tabular}{|ll|r|r|}
\hline \multirow{2}{*}{ Model } & \multicolumn{2}{|c|}{ Collinearity Statistics } \\
\cline { 3 - 4 } & Tolerance & \multicolumn{2}{|c|}{ VIF } \\
\hline $1 \quad$ (Constant) & .979 & 1.022 \\
& Love of money & .979 & 1.022 \\
& Religiusitas & .993 & 1.007 \\
& nilai etis & & \\
\hline
\end{tabular}

a. Dependent Variable: kecenderungan kecurangan akuntansi

Dari tabel diatas dapat dilihat nilai VIF(variance influence factor) untuk ketiga variabel bebas diaatas hasilnya VIF $\leq 10$ ini berarti variabel bebas ketiganya tidak memperlihatkan adaanya korelasi yang cukup kuat antara variabel bebas

\section{Hasil uji heteroskedastisitas}

Uji heteroskedastisitas bertujuan untuk menguji apakah dalam model regresi terjadi ketidaksamaan variance dari residual satu pengamatan kepengamatan yang lain,jika variance dari residual satu pengamatan ke pengamatan yang lain tetap,maka disebut homoskedastisitas dan jika berbeda disebut heteroskedastisitas.Model regresi yang baik adalah yang homoskedastisitas atau tidak terjadi heteroskedastisitas. ${ }^{26}$

\footnotetext{
${ }^{26}$ Imam Ghozali, Aplikasi Multivariat dengan program Spss 21 (Semarang;Undip, 2013), h. 139
} 
62 $\mid$ MUSAWA, Vol. 12 No.1 Juni $2020: 49-72$

Gambar 4

Scatterplot

Dependent Variable: kece kecurangan akuntansi

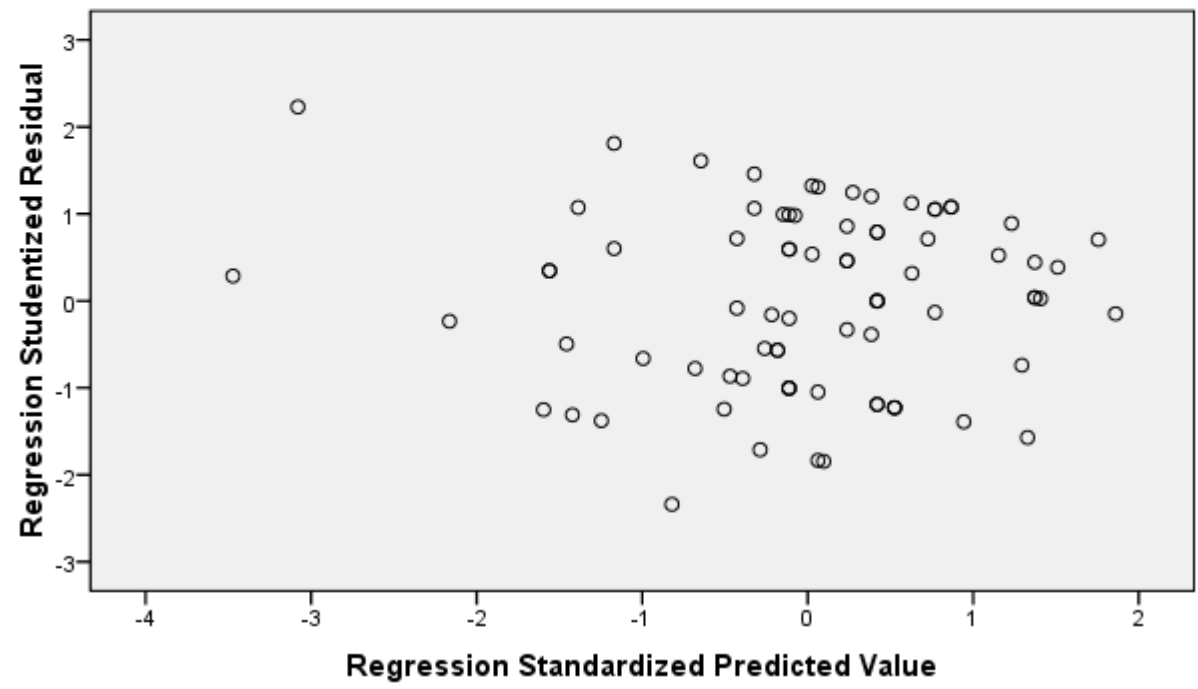

Dari hasil out put grafik scaterplot diatas garis titik -titik menyebar secara acak serta tersebar baik diatas maupundibawah angka 0 pada sumbu y .Hai ini disimpulkan ahwa tidak terjadi heteroskedastisitas pada model regresi ,sehingga model regresi layak dipakai.

\section{E. Hasil Analisis Regresi berganda}

Analisis regresi berganda berfungsi untuk mengetahui ada tidaknya pengaruh variabel bebas dan variabel terikat. 
Irham Pakkawaru, Pengaruh Love of Money ... | 63

Gambar 5

Model Summary

\begin{tabular}{|l|r|r|r|r|}
\hline Model & $\mathrm{R}$ & \multicolumn{1}{c|}{ R Square } & Adjusted R Square & $\begin{array}{c}\text { Std. Error of the } \\
\text { Estimate }\end{array}$ \\
\hline 1 & $.350^{\mathrm{a}}$ & .123 & .088 & 2.56738 \\
\hline
\end{tabular}

a. Predictors: (Constant), nilai etis, Religiusitas, Love of money

b. Dependent Variable: kece kecurangan akuntansi

Dari tampilan output spss diatas model summary berdasarkan adjusted $\mathrm{R}$ square adalah 0.088 haiini berarti 8,8 kecenderungan kecuranngan akuntansi dapt dijelaskan ketiga variabel love of money,religiusitas dan nilai etis dan sisanya dipengaruhi oleh variabel lain.

Gambar 6

ANOVA $^{\text {b }}$

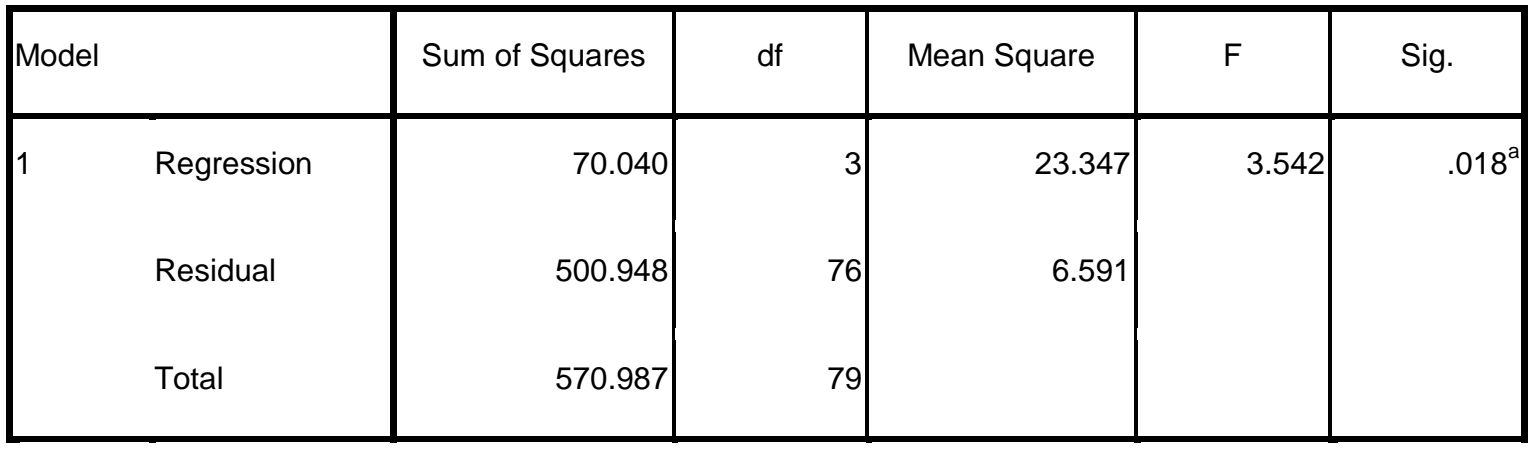

a. Predictors: (Constant), nilai etis, Religiusitas, Love of money

b. Dependent Variable: kecenderungan kecurangan akuntansi 
64 | MUSA WA, Vol. 12 No.1 Juni $2020: 49-72$

Dari uji Anova atau F tset didapat nilai f bhitung sebesar 3.542 dengan nilai probabilita 0.018.karena propabilita jauh lebih kecil dari 0.05 maka model regresi dapat digunakan untuk memprediksi kecenderungan kecurangan akuntansi atau dapat dikatakan bahwa love of money, religiusitas nilai etis secara bersama -sama berpengaruh terhadap kecenderunagn kecurangan akuntasni mahasiswa ekonomi di Kota Palu.

Gambar 7

Coefficients $^{a}$

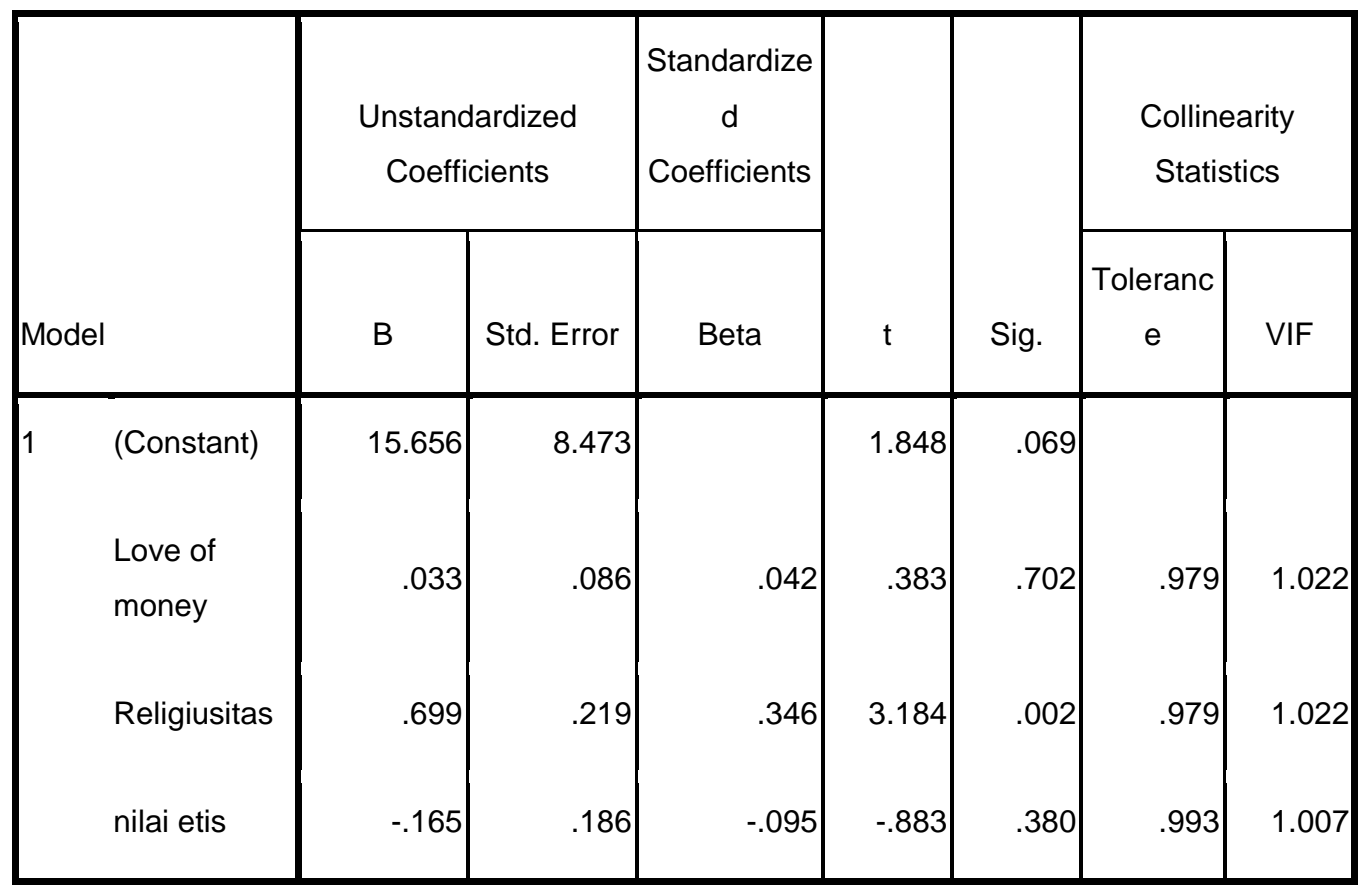

a. Dependent Variable: kece kecurangan akuntansi

Dari ketiga variabel inpenden yang dimasukkan kedalam model regresi variabel love of money dan nilai etis tidak signifikan hal ini dapat dilihat dari probabilitas signifikansi untuk love of money sebessar 0.702 dan nilai etis sebesar 0.380 dan keduanya jauh diatas 0.05 sedangkan religiusitas signifikan pada 0.05 . 


\section{F. Hasil Uji Residual}

\section{Moderating 1}

Gambar 8

Coefficients $^{\mathrm{a}}$

\begin{tabular}{|l|r|r|r|r|r|}
\hline \multirow{2}{*}{ Model } & \multicolumn{2}{|c|}{$\begin{array}{c}\text { Unstandardized } \\
\text { Coefficients }\end{array}$} & $\begin{array}{c}\text { Standardized } \\
\text { Coefficients }\end{array}$ & & \multirow{2}{*}{ Sig. } \\
\cline { 2 - 5 } & B & Std. Error & Beta & \multicolumn{1}{|c|}{$\mathrm{t}$} & .652 \\
\hline $1 \quad$ (Constant) & 1.225 & 2.708 & & .452 & .561 \\
$\begin{array}{l}\text { Kecenderungan } \\
\text { kecurangan } \\
\text { akuntansi }\end{array}$ & .043 & .074 & .066 & .583 & .561 \\
\hline
\end{tabular}

Persamaan yang didapat

Moderating 1

$|\mathrm{e}|=1.225+0.043 \mathrm{kecenderungan} \mathrm{kecurangan}$ akuntansi ......1

Berdasarkan hasil yang di dapat pada gambar 8 dimana koefisien regresi dari kecenderungan kecurangan akuntansi bernilai 0.043 yang berarti ada ketidakcocokan (lack of fit) pada interaksi antara love of money dan idealisme tidak berpengaruh positif terhadap terhadap kecenderungan kecurangan akuntansi.nilai t hitung yang diperoleh sebesar 0.583 pada taraf signifikansi $0.561 \geq 0.05$ sehingga disimpulkan bahwa idealisme bukan sebagai variabel moderating pada hubungan antara love of money terhadap kecenderungan kecurangan akuntansi pada mahasiswa ekonomi kota Palu.Terlihat variabel kecenderungan kecurangan akuntansi tidak signifikan dan nilai 
66 | MUSA WA, Vol. 12 No.1 Juni $2020: 49-72$

koofesien parameternya positif maka dapat disimpulkan bahwa variabel idealisme bukan sebagai variabel moderating.

Moderating 2

Gambar 9

Coefficients $^{\mathrm{a}}$

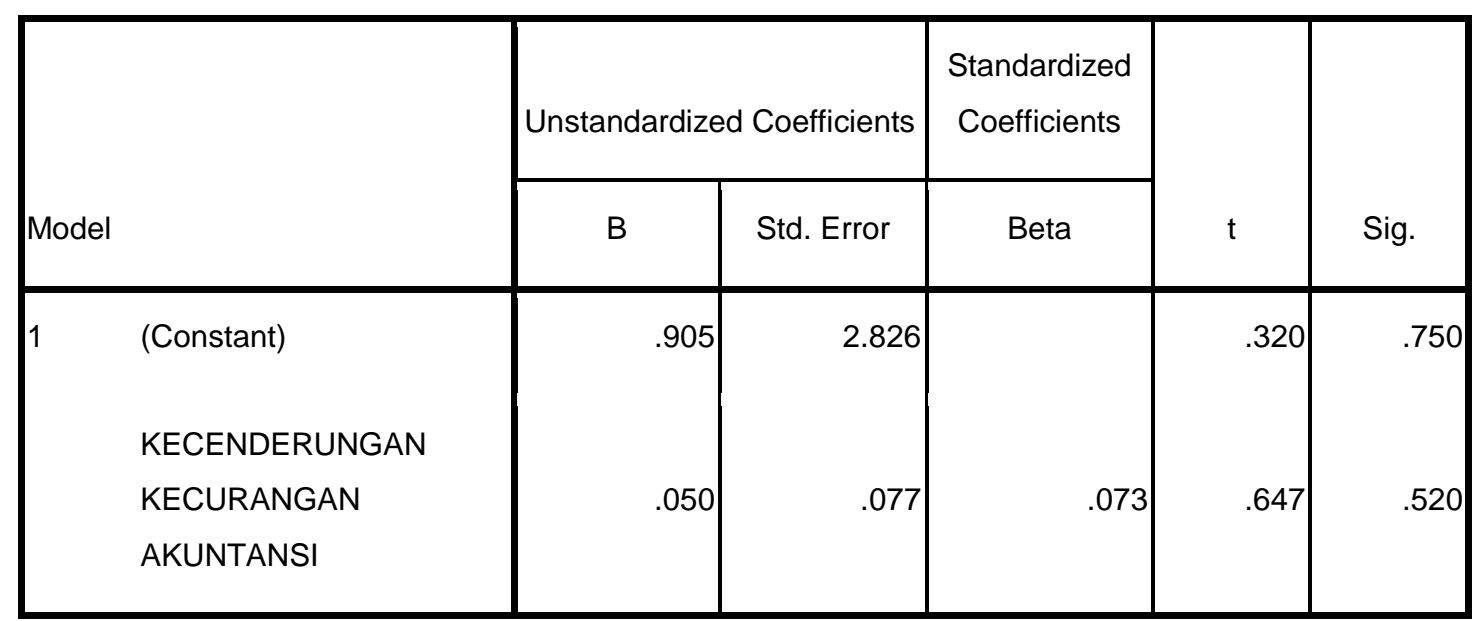

a. Dependent Variable: ABres2

Persamaan yang diperoleh

$|\mathrm{e}|=0.905+0.050$ kecenderungan kecurangan akuntansi ......2

Berdasarkan hasil yang di dapat pada gambar 9 dimana koefisien regresi dari kecenderungan kecurangan akuntansi bernilai 0.050 yang berarti ada ketidakcocokan (lack of fit) pada interaksi antara religiusitas dan idealisme tidak berpengaruh positif terhadap terhadap kecenderungan kecurangan akuntansi.nilai t hitung yang diperoleh sebesar 0.647 pada taraf signifikansi $0.520 \geq 0.05$ sehingga disimpulkan bahwa idealisme bukan sebagai variabel moderating pada hubungan variabel religiusitas terhadap kecenderungan kecurangan akuntansi pada mahasiswa ekonomi kota 
Palu.Terlihat variabel kecenderungan kecurangan akuntansi tidak signifikan dan nilai koofesien parameternya positif maka dapat disimpulkan bahwa variabel idealisme bukan sebagai variabel moderating.

Moderating 3

Gambar 10

Coefficients $^{\mathrm{a}}$

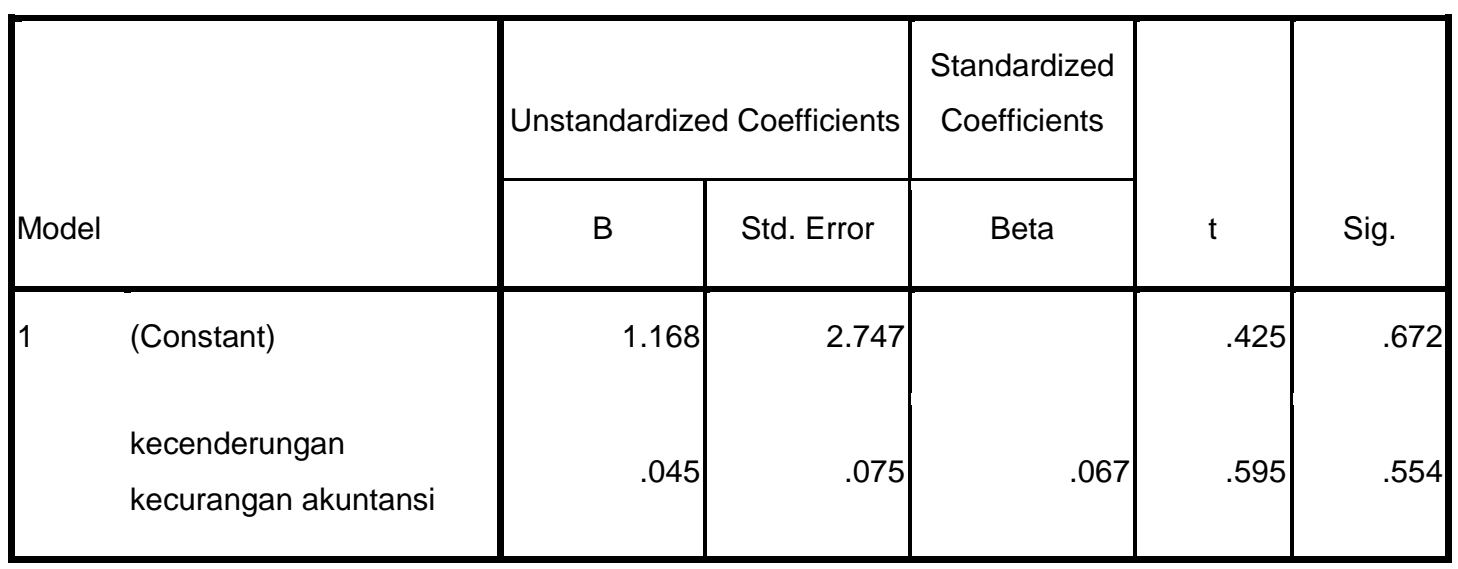

a. Dependent Variable: abres3

Persamaan yang diperoleh

$|\mathrm{e}|=1.168+0.045$ kecenderungan kecurangan akuntansi ......3

Berdasarkan hasil yang di dapat pada gambar 13 dimana koefisien regresi dari kecenderungan kecurangan akuntansi bernilai 0.050 yang berarti ada ketidakcocokan (lack of fit) pada interaksi antara nilai etis dan idealisme tidak berpengaruh positif terhadap terhadap kecurangan akuntansi.nilai t hitung yang diperoleh sebesar 0.647 pada taraf signifikansi $0.520 \geq 0.05$ sehingga disimpulkan bahwa idealisme bukan sebagai variabel moderating pada hubungan variabel religiusitas terhadap kecenderungan kecurangan akuntansi pada mahasiswa ekonomi kota Palu.Terlihat 
68 | MUSA WA, Vol. 12 No.1 Juni $2020: 49-72$

variabel kecenderungan kecurangan akuntansi tidak signifikan dan nilai koofesien parameternya positif maka dapat disimpulkan bahwa variabel idealisme bukan sebagai variabel moderating.

\section{G. Hasil Uji Beda T test}

Hasil Uji beda idealisme antara mahasiswa ekonomi kota laki-laki dan perempuan

Group Statistics

\begin{tabular}{|c|c|c|c|c|c|}
\hline & jenis_kelamin & $\mathrm{N}$ & Mean & Std. Deviation & Std. Error Mean \\
\hline \multirow[t]{2}{*}{ nilai } & laki-laki & 31 & 26.9355 & 2.78011 & .49932 \\
\hline & perempuan & 49 & 28.4082 & 2.71507 & .38787 \\
\hline
\end{tabular}

Independent Samples Test

\begin{tabular}{|c|c|c|c|c|c|c|c|c|c|}
\hline & \multicolumn{2}{|c|}{$\begin{array}{l}\text { Levene's Test for } \\
\text { Equality of } \\
\text { Variances }\end{array}$} & \multicolumn{7}{|c|}{ t-test for Equality of Means } \\
\hline & & & & & \multirow{2}{*}{$\begin{array}{l}\text { Sig. }(2- \\
\text { tailed) }\end{array}$} & \multirow{2}{*}{$\begin{array}{c}\text { Mean } \\
\text { Differenc } \\
\mathrm{e}\end{array}$} & \multirow{2}{*}{$\begin{array}{c}\text { Std. } \\
\text { Error } \\
\text { Differenc } \\
\text { e }\end{array}$} & \multicolumn{2}{|c|}{$\begin{array}{c}95 \% \text { Confidence } \\
\text { Interval of the } \\
\text { Difference }\end{array}$} \\
\hline & $\mathrm{F}$ & Sig. & $\mathrm{t}$ & $d f$ & & & & Lower & Upper \\
\hline $\begin{array}{c}\text { nilai Equal variances } \\
\text { assumed }\end{array}$ & .381 & .539 & -2.342 & 78 & .022 & -1.47268 & .62887 & -2.72466 & -.22070 \\
\hline $\begin{array}{l}\text { Equal variances } \\
\text { not assumed }\end{array}$ & & & -2.329 & $\begin{array}{r}62.82 \\
9\end{array}$ & .023 & -1.47268 & .63227 & -2.73624 & -.20912 \\
\hline
\end{tabular}


Terlihat bahwa rata-rata idealisme laki-laki 26.93 dan perempuan 28.40.secara absolut jelas bahwa rata-rata idealisme perempuan dan laki-laki berbeda.bahwa nilai t -2.342 dan sig 0.022 jadi dapatdi simpulkan bahwa idealisme laki-laki dan perempuan berbeda

\section{Hasil Uji beda kecenderungan kecurangan antara mahasiswa ekonomi kota laki-laki dan perempuan}

Group Statistics

\begin{tabular}{|c|c|c|c|c|c|}
\hline & $\begin{array}{l}\text { jenis_kelami } \\
\mathrm{n}\end{array}$ & $\mathrm{N}$ & Mean & Std. Deviation & $\begin{array}{c}\text { Std. Error } \\
\text { Mean }\end{array}$ \\
\hline nilaikecunganakntnsi & $\begin{array}{l}\text { laki-laki } \\
\text { perempuan }\end{array}$ & $\begin{array}{l}31 \\
49\end{array}$ & $\begin{array}{l}36.7419 \\
36.5510\end{array}$ & $\begin{array}{l}2.63271 \\
2.73146\end{array}$ & $\begin{array}{l}.47285 \\
.39021\end{array}$ \\
\hline
\end{tabular}

\section{Independent Samples Test}

\begin{tabular}{|c|c|c|c|c|c|c|c|c|c|c|}
\hline & & \multicolumn{2}{|c|}{$\begin{array}{c}\text { Levene's Test for } \\
\text { Equality of } \\
\text { Variances }\end{array}$} & \multicolumn{7}{|c|}{ t-test for Equality of Means } \\
\hline & & \multirow[b]{2}{*}{$\mathrm{F}$} & \multirow[b]{2}{*}{ Sig. } & \multirow[b]{2}{*}{$\mathrm{t}$} & \multirow[b]{2}{*}{ df } & \multirow{2}{*}{$\begin{array}{l}\text { Sig. (2- } \\
\text { tailed) }\end{array}$} & \multirow{2}{*}{$\begin{array}{c}\text { Mean } \\
\text { Differen } \\
\text { ce }\end{array}$} & \multirow{2}{*}{$\begin{array}{c}\text { Std. } \\
\text { Error } \\
\text { Differen } \\
\text { ce }\end{array}$} & \multicolumn{2}{|c|}{$\begin{array}{c}95 \% \text { Confidence } \\
\text { Interval of the } \\
\text { Difference }\end{array}$} \\
\hline & & & & & & & & & Lower & Upper \\
\hline $\begin{array}{l}\text { nilaikecung } \\
\text { anakntnsi }\end{array}$ & $\begin{array}{l}\text { Equal } \\
\text { variances } \\
\text { assumed }\end{array}$ & .000 & 1.000 & .309 & 78 & .758 & .19092 & .61823 & 1.03988 & 1.42171 \\
\hline
\end{tabular}


70 | MUSA WA, Vol. 12 No.1 Juni $2020: 49-72$

\section{Independent Samples Test}

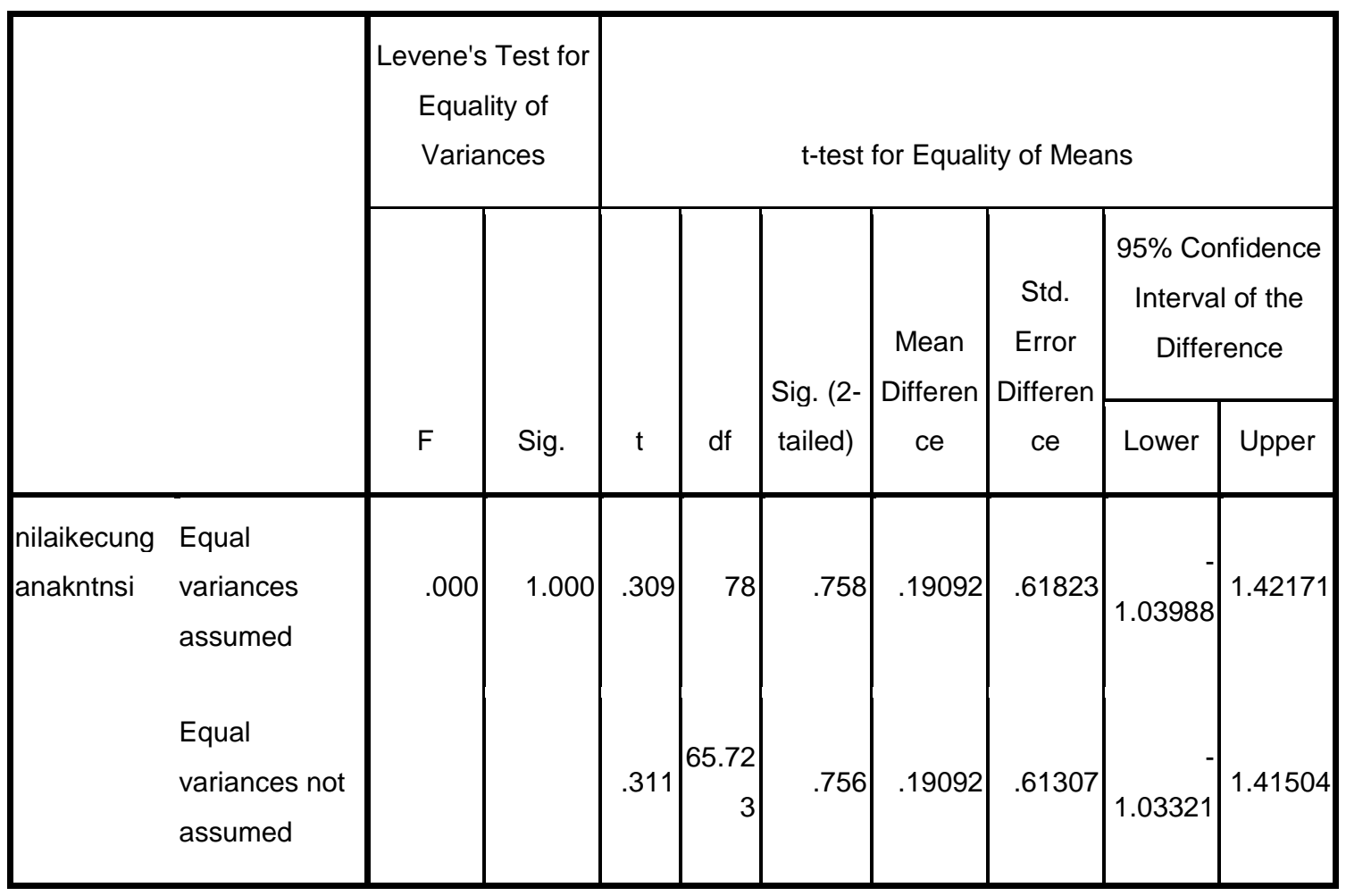

Terlihat bahwa rata-rata kecenderungan kecurangan akuntansi mahasiswa ekonomi Kota Palu laki-laki 36.74 dan perempuan 36.55.secara absolut jelas bahwa rata-rata idealisme perempuan dan laki-laki tidak berbeda.bahwa nilai t .309 dan sig 0.758 jadi dapat disimpulkan bahwa idealisme laki-laki dan perempuan tidak berbeda.

\section{KESIMPULAN}

A. Hasil pengujian hipotesis bahwa disimpulkan bahwa love of money, religiusitas, nilai etis berpengaruh secara simultan atau secara serempak terhadap Hasil pengujian hipotesis bahwa disimpulkan bahwa love of money, religiusitas, nilai etis berpengaruh secara simultan atau secara serempak terhadap kecenderungan kecurangan akuntansi mahasiswa ekonomi Kota Palu. 
B. Hasil pengujian hipotesis bahwa love of money tidak berpengaruh secara parsial terhadap kecenderungan kecurangan akuntansi mahasiswa ekonomi Kota Palu.

C. Hasil pengujian hipotesis bahwa religiusitas berpengaruh secara parsial terhadap kecenderungan kecurangan akuntansi mahasiswa ekonomi Kota Palu.

D. Hasil pengujian hipotesis bahwa nilai etis tidak berpengaruh secara parsial terhadap kecenderungan kecurangan akuntansi mahasiswa ekonomi Kota Palu.

E. Hasil pengujian hipotesis idealisme bukan sebagai variabel moderating antara love of money terhadap kecenderungan kecurangan akuntansi mahasiswa ekonomi Kota Palu.

F. Hasil pengujian hipotesis idealisme bukan sebagai variabel moderating antara Religiusitas terhadap kecenderungan kecurangan akuntansi mahasiswa ekonomi Kota Palu.

G. Hasil pengujian hipotesis idealisme bukan sebagai variabel moderating antara Religiusitas terhadap kecenderungan kecurangan akuntansi mahasiswa ekonomi Kota Palu.

H. Hasil pengujian hipotesis idealisme bukan sebagai variabel moderating antara nilai etis terhadap kecenderungan kecurangan akuntansi mahasiswa ekonomi Kota Palu.

I. Hasil pengujian hipotesis terdapat perbedaan idealisme laki- laki dan perempuan mahasiswa ekonomi Kota Palu.

J. Hasil pengujian hipotesis tidak terdapat kecenderungan kecurangan akuntansi idealisme laki- laki dan perempuan mahasiswa ekonomi Kota Palu.

\section{DAFTAR PUSTAKA}

Aida A Mardiyah (2006). Teori akuntansi konsep dan empiris Malang. : BP STIE Malang Kucecwara.

Celvia Dhian Charismawati (2011) Analisis hubungan antara love of money dengan persepsi etika Semarang: Undip. 
72 | MUSA WA, Vol. 12 No.1 Juni $2020: 49-72$

Firdausia oktaviana Analisis pengaruh love of money,Gender,religius terhadap persepsi etis mahasiswa akuntansi .UIM Malang

Lukita Tripermata(2016) Pengaruh loveof money, nilai etis mahasiswa dan komitmen organisasi terhadapkecenderungan kecurangan akuntansi dengan gender sebagai variabel moderating.Palembang :Jurnal ekonomi ilmiah vol 7.

Husein Umar. (2011). Metode Penelitian untuk Skripsi dan Tesis Bisnis. Jakarta: Rajawali Press

Imam Ghozali. (2001). Aplikasi Analisis Multivariate dengan Program SPSS. Semarang: BP UNDIP.

Islachul imam memahami makna religiusitas (Http ;// islachul 08.blogspot.co.id/2014/02/ pada tanggal 04 April 2017.

Jalaluddin. (2010). Psikologi Agama. Jakarta: PT. Raja Grafindo Persada.

Muhammad djakfar ( 2009) Anatomi perilaku bisnis dialetika etika dengan realias Malang; Uin Press.

Jogiyanto Hartono. (2004). Pengenalan Komputer: Dasar Ilmu Komputer, Pemrograman, Sistem Informasi dan Intelegensi Buatan. Yogyakarta: Andi

Putu Pandhu Prabowo dan A.A.G.P Widanaputra (2018) Pengaruh Love of Money. Machiavellian dan idealisme pada Persepsi etis mahasiwa Akuntansi. Jurnal Akuntansi udayana Bali Vol.23 1April 2018.

Rindayanti,Dekeng Setyo budiarto.(2017) Hubungan love of money,machiavellian dengan persepsi etis;Analisis berdasarkan perspektif gender Yogyakarata jurnal ilmu akuntansi Vol 10(2) Oktober 2017.

Suliyanto, Ekonomi terapan,teori dan aplikasi dengan sppss,CV Andi offset 2011.

Sugiyono,metode penelitian bisnis,Pendekatan kuantitatif kualitatif, $R \& D$ Cet 13 Bandung: Alfabeta, 2009.

, Statistik Untuk penelitian, cet IX Bandung: Alfabeta, 2006.

Theodorus M Tuanakota (2010). Akuntansi Forensik Dan audit Investigatif. Jakarta Salemba Empat. 